\title{
Migrant women farm workers in the occupational health literature
}

\author{
Rima R. Habib ${ }^{\mathrm{a},{ }^{*}}$ and Fadi A. Fathallah ${ }^{\mathrm{b}}$ \\ ${ }^{a}$ Faculty of Health Sciences, American University of Beirut, Lebanon \\ ${ }^{\mathrm{b}}$ Department of Biological and Agricultural Engineering, University of California, Davis, USA
}

\begin{abstract}
Little attention has been given to the vulnerable populations of migrant women agricultural workers. A systemic review in PubMed was carried out (1990-2008) using terms related to migrant agricultural workers, with specific focus on women. Case studies from Lebanon and California are presented to highlight key physical, psychosocial, and cultural risk factors among these working populations. The review revealed a host of potential problems that span from pesticide exposure and musculoskeletal disorders to socio-cultural barriers. Comprehensive exposure-outcome and intervention studies focusing specifically on migrant women in agriculture are lacking. In depth studies focusing on the work environment of migrant women workers in the agricultural sector are needed. Personal and environmental factors that influence health should be considered in any effective intervention aiming to influence policy making and have a positive impact on these vulnerable working populations.
\end{abstract}

Keywords: Migrant workers, women, agricultural work, physical and psychosocial factors, health

\section{Introduction}

The agriculture sector employs about half the world's entire workforce, with an estimate of 1.3 billion workers [35]. Globally, women account for about $40 \%$ of the workforce in agriculture, and regionally, they represent $47 \%$ in Africa, $17 \%$ in Latin America and the Caribbean, $44 \%$ in Asia, and $21 \%$ in the US $[36,38,78]$.

Migrant women agricultural workers are exposed to a myriad of occupational hazards and stressors including injuries; pesticide illnesses; reproductive health problems; respiratory, dermatological, and infectious diseases and Musculoskeletal Disorders (MSDs), among others. In addition, migrant women may face a range of socio-cultural problems due to their transient status. Unfortunately, these health and

\section{Results}

The 81 articles identified by the PubMed search spanned a range of occupational health issues. The majority of study designs were quantitative in nature, psychosocial problems have been largely ignored by occupational health professionals.

\section{Methods}

This paper is a systematic review of the burdens and health problems faced by migrant women agricultural workers throughout the world. PubMed database was searched for articles in peer-reviewed journals published in the years 1990-2008.

The search identified 128 articles in PubMed, out of which 47 papers were excluded because they did not meet the general criterion; for example, the focus was on children or adolescents, males only, or non agricultural work. Hence, 81 relevant papers from the PubMed search were selected.

but several qualitative, intervention, and case report studies were also identified. This review focused on the burdens faced by migrant women agricultural workers, including: 1) psychosocial and cultural problems, and 2) physical health problems.

\footnotetext{
${ }^{*}$ Corresponding author. E-mail: rima.habib@aub.edu.lb. Faculty of Health Sciences, American University of Beirut, 3 Dag Hammarskjold Plaza, 8th floor, New York, NY 10017-2303, USA. Phone: +961-1-350000 Ext. 4630. Fax: +961-1-744470
} 


\subsection{Psychosocial and cultural problems}

Psychosocial, cultural, and legal barriers that may contribute to negative health outcomes to migrant female agriculture workers include lack of stable residence and social support, linguistic and cultural barriers, discrimination and fear of legal persecution for some, limited access to health care services, lack of safety training and oversight, acceptance of highrisk tasks and precarious job conditions. The additional burden of homemaking and raising a family compounds the psychosocial problems faced by migrant women agricultural workers.

The social changes experienced by migrant women workers, including the loss of social network and support [37] constitute additional psychosocial burdens. Discrimination against migrant workers has been reported in the form of racism, sexism, disability, and health conditions, in addition to discrimination based on national origin or immigration status [17-18].

Similar to migrant workers in other industries $[23,39,87]$, migrant women agricultural workers are likely to report general feelings of displacement, geographical and social isolation, loneliness and stress [48], as well as not being provided with a safe work environment, safety training [4] or personal protection equipment.

\subsection{Physical health problems}

Several studies have shown that migrant workers, in general, and agricultural workers, in particular, commonly have higher rates of occupational injuries and fatalities than non-migrant workers [6,8$9,19,47,49,53,65]$. This may be due to the fact that migrant workers tend to be concentrated in high-risk industries, such as agriculture and construction, and they usually perform high-risk jobs within these industries.

The diseases and illnesses generally experienced by women agricultural workers are expected to be exacerbated in vulnerable migrant women working in agriculture due to the added complex socio-cultural burdens. These diseases have been reported to be due to exposure to various substances commonly present around agricultural environments, including grain dust, gases and fumes from confined animal environments and silos, and mold and bacteria in grain and hay, among others [42,58,86]. Agricultural workers are also commonly exposed to pathogens that can cause various diseases and disorders $[43,54-$ 55].

Pesticide exposure in agricultural environments is one of the major causes of acute and chronic illnesses among workers. The health effect of pesticide exposure varies by many factors, including crop type, chemicals used, dosage, and the application mode, among other environmental and personal factors $[3,12-13,21,32,40,50,66,68,75,93]$. Several studies have shown the adverse effects of pesticide exposure to women working in agricultural environments and their children with a host of negative reproductive outcomes $\quad[2,7,14,16,22,28-30,44,62-63,73,88-91]$. Our literature review revealed that pesticide training and knowledge about safe and proper procedures for storing, handling and applying various pesticides could reduce the adverse health outcomes due to exposure to these toxins $[4,20,31,67,72,74,79]$.

\subsubsection{Musculoskeletal disorders in agriculture}

Musculoskeletal disorders (MSDs) are the most common of all occupational non-fatal injuries and illnesses for agricultural workers [52-53,81-82,84].

While, in general, women in agriculture tend to not perform tasks that require very forceful exertions (e.g., lifting heavy loads), they do tend to perform tasks that require frequent and repetitive actions, such as manual planting, harvesting, and maintaining plants and soils. These types of tasks have been shown to be associated with MSDs of the lower back (Low Back Disorders; LBDs) and the upper limbs (Cumulative Trauma Disorders; CTDs) [26-27,59$60]$. Women workers, especially in developing countries, are expected to be at risk for developing MSDs due to the added physical burden of performing household work [33-34]. Furthermore, women agricultural workers generally have a low socioeconomic status with a higher burden of disease.

The added burden of housework on women's musculoskeletal health has been generally ignored in most past studies. Regardless of their employment status, women remain largely responsible for housework and childcare tasks; activities that have clear implications for their health and well-being. Women's domestic labor (i.e., housework) remains largely unexplored in the literature on migrant women's health. 


\subsection{Case studies}

To highlight some of the unique burdens faced by migrant women farm workers, case studies from California and Lebanon are presented.

\subsubsection{California \\ Overview of California agriculture}

California is the US largest agricultural state with roughly $50 \%$ of the nation's fruits, vegetables, and horticultural specialty production occurring in California [11,61]. Agriculture is one of the largest industries in the state, with estimated cash receipts exceeding \$27 billion $[45,53,80,83]$. California agriculture relies heavily on migrant and seasonal workers, who account for about two-thirds of the total workforce, and come mainly from Mexico and other Central American countries, [53,58,83].

Migrant women in California agriculture

Women account for about $26 \%$ of workers who perform seasonal agricultural services in California [77-78]. The literacy level for both migrant men and women workers is very low $(71 \%$ finishing eighth grade or lower) [78]. Being single and uneducated puts migrant women agricultural workers in California in disadvantageous social and legal circumstances, and hence, the women usually face a host of psychosocial burdens. These women tend to have limited social networks and support and may struggle to acculturate in the local society.

Housing and working conditions

The housing conditions of migrant agricultural workers, in general, are considered sub-standard [85]. About $50 \%$ of the housing for hired farm workers in California is found to be overcrowded, and $25 \%$ is found to be extremely overcrowded. Many of the housing structures occupied by migrant workers are irregular structures not intended for human habitation, with a sizeable proportion lacking either plumbing or food preparation facilities, or both $[83,85]$. The added burden of homemaking is expected to exacerbate the health and psychosocial effects of poor working and housing conditions that are commonly faced by migrant women workers in California and elsewhere. Key health problems include pesticide illness, respiratory disease, infectious disease, dermatological disease and MSDs [27,53,58,83].

\subsubsection{Lebanon}

Overview of agriculture in Lebanon

Lebanon's economy relies substantially on the agricultural sector, with almost $12 \%$ of the GDP gen- erated from agricultural activities (compared to an average of $5 \%$ for the rest of the world). An estimated $7.3 \%$ of the "official" workforce of Lebanon is agricultural workers.

Migrant agricultural workers in Lebanon

It is widely recognized that most migrant workers in the agricultural sector come from Syria. In general, the number of Syrian laborers working in various Lebanese sectors has been reported to fluctuate between 200,000 and one million, with an overwhelming majority working illegally $[76,92]$. The official number for Syrian workers in various Lebanese sectors was estimated at only 471 in 2006 [10].

Women agricultural workers in Lebanon, are exposed to a number of occupational hazards, including exposure to pesticides [69-71]. They also have increased risk factors for respiratory, infectious, and dermatological diseases, and typical MSD (from stooped work, repetitive motion, awkward body postures, prolonged kneeling, etc.).

Olive industry in Lebanon

It is estimated that there are about 13 million olive trees in Lebanon, covering more than $20 \%$ of the cultivated land, with $40 \%$ being in the Northern region of the country [24]. Olive picking in Lebanon is mostly manually performed [41] by Syrian migrant men and women agricultural workers.

Migrant women in the olive industry

Women involved in harvesting the olives are seasonal agricultural workers who come with their families from remote disadvantaged communities in Syria. They are generally poor, of low literacy level, and in need of work. These women are rarely directly paid for harvesting the olives; it is generally the husband or the male head of household who is paid on behalf of all workers in his family.

Housing and working conditions

During the harvesting season, the migrant olive workers occupy temporary residential units put inplace by the olive orchard owners. Poor environmental housing conditions prevail in these units. They generally suffer from dampness, leaks in rainy weather, improper ventilation, lack of sunlight, in addition to crowding. Two or three families sometimes occupy the same unit, leading to a situation of pooled consumption in which they all share the shelter, food and heating.

Due to their transient living arrangement, undocumented worker status, and discrimination, migrant women olive harvesters have limited access to medical, social, and governmental services.

Women hand pick the olives either directly from the trees, or more commonly, pick the fallen olives 
from the ground (usually on plastic or cloth blankets). The postures assumed by these women (stooping, kneeling, and twisting) are likely to expose them to MSDs risk factors of the lower back and knees [27]. In addition, the repetitive and rapid hand picking expose them to the risk of developing MSDs of the hand and wrist (e.g., carpal tunnel syndrome, tendinitis, etc.) $[25,56-57]$.

\section{Discussion}

Many countries in the world have a shortage of labor in the agriculture industry and rely heavily on migrant and seasonal workers, of whom women make up a sizeable proportion. Due to their migratory and transitory status, migrant women workers are an especially vulnerable population in agriculture. They face a host of unique and complex set of psychosocial and cultural burdens, which makes them particularly vulnerable to the existing physical hazards commonly faced by agricultural workers.

The systematic literature review revealed several concerns related to the research done on migrant women workers in the agricultural sector around the world. With the increased reliance on migrant and seasonal workers especially in Europe and Asia, more attention should be paid to the complex issues and burdens faced by migrant populations of the agriculture sector in both developed and developing countries around the world. There is a thin literature on interventions undertaken on migrant agricultural workers. Furthermore, poverty, legal issues, deportation, low education, discrimination, exploitation, lack of union for the protection of rights, limited access to health services, lack of insurance and workers' compensation, and the lack of social justice, are not featured in any of the published interventions. Instead, the research mainly focused on personal behavioral factors that affect migrant agricultural workers' health, such as using personal protective equipment, receiving training on safety issues, and complying with safety standards.

The case studies from California and Lebanon demonstrate some of the unique problems faced by migrant women agricultural workers. First, the transient nature of this migrant population makes work arrangements rather informal and lacking the for$\mathrm{mal} /$ legal contracts commonly practiced in other industries. This may expose the women to economic exploitation and limit their economic betterment. The transitory situation also commonly results in a limited social network and social support among the women. Second, the high number of unauthorized workers among migrant women agricultural workers places unique barriers to this population for accessing health and social benefits and services that is compounded by the continuous fear of retribution and/or deportation. The problem is further complicated by potential language and dialect barriers, as in the case of California and Lebanon, respectively. These issues raise serious questions about the exploitation and discrimination faced by these women in agriculture. Lastly, working women in general face the unique situation of double-burden stemming from paid work and housework.

At the basic level, descriptive research is needed since there is no detailed information about the issues and problems faced by these women populations. It is evident that basic epidemiological studies are needed to identify the occupational and nonoccupational risk factors encountered by migrant women in agriculture.

Adopting a community based participatory research (CBPR) approach has proved to be conducive to successful research outcomes and interventions [5,15,40,50-51,64,66]. A CBPR approach allows exploring any situation from both the researchers' scientific-academic perspective and the community's practical perspective $[1,46]$.

The problems faced by migrant women agricultural workers are multi-layered and are both occupational and non-occupational in nature. Researchers have to acknowledge this population's complex and intricate situation that spans a wide range of issues.

Potential interventions should consider structural, cultural, physical, and psychosocial factors, and incorporate both behavioral and structural elements, such as training, work organization and workplace structural modifications. Governments can take a pragmatic approach to solve the undocumented working status of migrant workers if foreign labor is proven to be needed in the agricultural sector. Bulat et al. (2006) proposed the "legalization" of agricultural workers as a solution for some of their problems. Policy implications and changes should be at the center of an effective intervention aiming to have a positive impact on these vulnerable working populations. Finally, information on the problems faced by migrant agricultural workers around the world may be disseminated by the national and international media by highlighting the vulnerability of this population, which would put pressure on stakeholders and governments to change. 


\section{Acknowledgements}

The authors thank the migrant agricultural workers who accepted to be studied. We express our gratitude to all the people who contributed time and effort in collecting information on migrant agricultural workers in California and Lebanon.

\section{References}

[1] A. Adams, N. Miller-Korth, D. Brown, Learning to work together: developing academic and community research partnerships, WMJ 103 (2) (2004) 15-19.

[2] T.E. Arbuckle, Z. Lin, L.S. Mery, An exploratory analysis of the effect of pesticide exposure on the risk of spontaneous abortion in an Ontario farm population, Environ Health Perspect 109 (8) (2001) 851-857.

[3] T.A. Arcury, S.A. Quandt, Pesticides at work and at home: exposure of migrant farmworkers, Lancet 362 (9400) (2003) 2021.

[4] T.A. Arcury, S.A. Quandt, C.K. Austin, J. Preisser, L.F Cabrera, Implementation of EPA's Worker Protection Standard training for agricultural laborers: an evaluation using North Carolina data, Public Health Rep 114 (5) (1999) 459-468.

[5] T.A. Arcury, S.A. Quandt, G.B. Russell, Pesticide safety among farmworkers: perceived risk and perceived control as factors reflecting environmental justice, Environ Health Perspect 110 Suppl 2 (2002) 233-240.

[6] L.S. Azaroff, C. Levenstein, D.H. Wegman, The occupational health of Southeast Asians in Lowell: a descriptive study, Int J Occup Environ Health 10 (1) (2004) 47-54.

[7] G.S. Berkowitz, J.G. Wetmur, E. Birman-Deych, J. Obel, R.H. Lapinski, J.H. Godbold, I.R. Holzman, M.S. Wolff, In utero pesticide exposure, maternal paraoxonase activity, and head circumference, Environ Health Perspect 112 (3) (2004) 388-391.

[8] P. Bollini, H. Siem, No real progress towards equity: health of migrants and ethnic minorities on the eve of the year 2000, Soc Sci Med 41 (6) (1995) 819-828.

[9] M. Carangan, K.Y. Tham, E. Seow, Work-related injury sustained by foreign workers in Singapore, Ann Acad Med Singapore 33 (2) (2004) 209-213.

[10] CAS, Statistical Yearbook-2006, Central Administration for Statistics (CAS), 2006

[11] CDFA, Agriculture Statistical Review, California Department of Food and Agriculture (CDFA) Agricultural Resource Directory 2001, 2002.

[12] T.J. Chain-Castro, R. Barron-Aragon, L. Haro-Garcia, Pesticide poisoning in Mexican seasonal farm workers, Int J Occup Environ Health 4 (3) (1998) 202-203.

[13] S. Ciesielski, D.P. Loomis, S.R. Mims, A. Auer, Pesticide exposures, cholinesterase depression, and symptoms among North Carolina migrant farmworkers, Am J Public Health 84 (3) (1994) 446-451.

[14] G.D. Coronado, E.M. Vigoren, B. Thompson, W.C. Griffith, E.M. Faustman, Organophosphate pesticide exposure and work in pome fruit: evidence for the take-home pesticide pathway, Environ Health Perspect 114 (7) (2006) 999-1006
[15] J.L. Crowe, M.C. Keifer, M.K. Salazar, Striving to provide opportunities for farm worker community participation in research, J Agric Saf Health 14 (2) (2008) 205-219.

[16] C.L. Curl, R.A. Fenske, J.C. Kissel, J.H. Shirai, T.F. Moate, W. Griffith, G. Coronado, B. Thompson, Evaluation of take-home organophosphorus pesticide exposure among agricultural workers and their children, Environ Health Perspect 110 (12) (2002) A787-792.

[17] A.B. de Castro, K. Fujishiro, E. Sweitzer, J. Oliva, How immigrant workers experience workplace problems: a qualitative study, Arch Environ Occup Health 61 (6) (2006) 249-258.

[18] A.B. de Castro, G.C. Gee, D.T. Takeuchi, Workplace discrimination and health among Filipinos in the United States, Am J Public Health 98 (3) (2008) 520-526.

[19] X. Dong, J.W. Platner, Occupational fatalities of Hispanic construction workers from 1992 to 2000 , Am J Ind Med 45 (1) (2004) 45-54

[20] P.D. Elkind, K. Pitts, S.L. Ybarra, Theater as a mechanism for increasing farm health and safety knowledge, Am J Ind Med Suppl 2 (2002) 28-35.

[21] L.S. Engel, M.C. Keifer, H. Checkoway, L.R. Robinson, T.L. Vaughan, Neurophysiological function in farm workers exposed to organophosphate pesticides, Arch Environ Health 53 (1) (1998) 7-14.

[22] B. Eskenazi, A.R. Marks, A. Bradman, L. Fenster, C. Johnson, D.B. Barr, N.P. Jewell, In utero exposure to dichlorodiphenyltrichloroethane (DDT) and dichlorodiphenyldichloroethylene (DDE) and neurodevelopment among young Mexican American children, Pediatrics 118 (1) (2006) 233-241.

[23] M.E. Facey, The health effects of taxi driving: the case of visible minority drivers in Toronto, Can J Public Health 94 (4) (2003) 254-257.

[24] FAO, LEBANON - Agricultural Census 1998 - Main Results, FAO, 2000.

[25] F.A. Fathallah, P.G. Dempsey, B.S. Webster, Cumulative Trauma Disorders in Industry, in: W. Karwowski, G. Salvendy (Eds.), Ergonomics in Manufacturing: Raising Productivity through Workplace Improvement, Society of Manufacturing Engineers, Dearborn, MI, 1998.

[26] F.A. Fathallah, J.M. Meyers, I. Janowitz, Stooped and Squatting Postures in the Workplace Conference Proceedings, in: F. Fathallah, J.M. Meyers, I. Janowitz (Eds.), Stooped and Squatting Postures in the Workplace, University of California Center for Occupational and Environmental Health, Oakland, California, 2004.

[27] F.A. Fathallah, B.J. Miller, J.A. Miles, Low back disorders in agriculture and the role of stooped work: scope, potential interventions, and research needs, J Agric Saf Health 14 (2) (2008) 221-245.

[28] R.A. Fenske, C. Lu, N.J. Simcox, C. Loewenherz, J. Touchstone, T.F. Moate, E.H. Allen, J.C. Kissel, Strategies for assessing children's organophosphorus pesticide exposures in agricultural communities, $\mathrm{J}$ Expo Anal Environ Epidemiol 10 (6 Pt 2) (2000) 662-671.

[29] L. Fenster, B. Eskenazi, M. Anderson, A. Bradman, A. Hubbard, D.B. Barr, In utero exposure to DDT and performance on the Brazelton neonatal behavioral assessment scale, Neurotoxicology 28 (3) (2007) 471-477.

[30] V.F. Garry, M. Harkins, A. Lyubimov, L. Erickson, L. Long, Reproductive outcomes in the women of the Red River Valley of the north. I. The spouses of pesticide applicators: pregnancy loss, age at menarche, and exposures to pesticides, J Toxicol Environ Health A 65 (11) (2002) 769-786. 
[31] L. Goldman, B. Eskenazi, A. Bradman, N.P. Jewell, Risk behaviors for pesticide exposure among pregnant women living in farmworker households in Salinas, California, Am J Ind Med 45 (6) (2004) 491-499.

[32] J.G. Grzywacz, S.A. Quandt, T.A. Arcury, Immigrant farmworkers' health-related quality of life: an application of the job demands-control model, J Agric Saf Health 14 (1) (2008) 79-92.

[33] R.R. Habib, I. Nuwayhid, M. Merhi, C. Myntti, Gendered Division of Household Responsibilities in the Urban Outskirts of Beirut, IV International Congress on Women Work \& Health, New Delhi, 2005, p. 74.

[34] R.R. Habib, I.A. Nuwayhid, J.S. Yeretzian, Paid work and domestic labor in disadvantaged communities on the outskirts of Beirut, Lebanon, Sex Roles 55 (5-6) (2006) 321-329.

[35] ILO, Facts on Agriculture, Vol. 2007, International Labour Organization (ILO), 2003.

[36] ILO, Global employment trends for women, International Labour Office (ILO), Geneva, Switzerland, 2007.

[37] ILO, Top on the agenda: Health and safety in agriculture, International Labour Office (ILO), Geneva, Switzerland, 2000.

[38] ILO, Towards a fair deal for migrant workers in the global economy, International Labour Conference, 92nd Session, International Labour Office (ILO), Geneva, Switzerland, 2004.

[39] D. Jackson, The multicultural workplace: comfort, safety and migrant nurses, Contemp Nurse 5 (3) (1996) 120-126.

[40] F. Kamel, T. Moreno, A.S. Rowland, L. Stallone, G. Ramirez-Garnica, D.P. Sandler, Recruiting a community sample in collaboration with farmworkers, Environ Health Perspect 109 Suppl 3 (2001) 457-459.

[41] W. Khoury, Overview of the Lebanese Olive Oil Industry, SRI International, Beirut, Lebanon, 2003.

[42] S.R. Kirkhorn, M.B. Schenker, Current health effects of agricultural work: respiratory disease, cancer, reproductive effects, musculoskeletal injuries, and pesticide-related illnesses, J Agric Saf Health 8 (2) (2002) 199-214.

[43] S. Koyadun, A. Bhumiratana, Surveillance of imported bancroftian filariasis after two-year multiple-dose diethylcarbamazine treatment, Southeast Asian J Trop Med Public Health 36 (4) (2005) 822-831.

[44] M. Lacasana, H. Vazquez-Grameix, V.H. Borja-Aburto, J. Blanco-Munoz, I. Romieu, C. Aguilar-Garduno, A.M. Garcia, Maternal and paternal occupational exposure to agricultural work and the risk of anencephaly, Occup Environ Med 63 (10) (2006) 649-656.

[45] A.C. Larson, Migrant and Seasonal Farmworker Enumeration Profiles Study California, prepared for the Migrant Health Program, Bureau of Primary Health Care, Health Resources and Services Administration, Department of Health and Human Services, 2000, pp. 1-26.

[46] R.D. Lasker, E.S. Weiss, R. Miller, Promoting collaborations that improve health, Educ Health (Abingdon) 14 (2) (2001) 163-172.

[47] K. Loh, S. Richardson, Foreign-born workers: trends in fatal occupational injuries, 1996-2001, Mon Labor Rev 45 (2004) 45-54.

[48] C.G. Magana, J.D. Hovey, Psychosocial stressors associated with Mexican migrant farmworkers in the midwest United States, J Immigr Health 5 (2) (2003) 75-86.

[49] L.A. McCauley, Immigrant workers in the United States: recent trends, vulnerable populations, and challenges for occupational health, AAOHN J 53 (7) (2005) 313-319.
[50] L.A. McCauley, M. Beltran, J. Phillips, M. Lasarev, D. Sticker, The Oregon migrant farmworker community: an evolving model for participatory research, Environ Health Perspect 109 Suppl 3 (2001) 449-455.

[51] L.A. McCauley, M.R. Lasarev, G. Higgins, J. Rothlein, J. Muniz, C. Ebbert, J. Phillips, Work characteristics and pesticide exposures among migrant agricultural families: a community-based research approach, Environ Health Perspect 109 (5) (2001) 533-538.

[52] S.A. McCurdy, D.J. Carroll, Agricultural injury, Am J Ind Med 38 (4) (2000) 463-480.

[53] S.A. McCurdy, S.J. Samuels, D.J. Carroll, J.J. Beaumont, L.A. Morrin, Agricultural injury in California migrant Hispanic farm workers, Am J Ind Med 44 (3) (2003) 225235.

[54] G. Mengistu, F. Balcha, S. Britton, Clinical presentation of onchocerciasis among indigenous and migrant farmers in southwest Ethiopia, East Afr Med J 76 (11) (1999) 635-638.

[55] G. Mengistu, F. Balcha, S. Britton, Co-infection of Onchocerca volvulus and intestinal helminths in indigenous and migrant farmers in southwest Ethiopia, Ethiop Med J 40 (1) (2002) 19-27.

[56] J.M. Meyers, J.A. Miles, J. Faucett, I. Janowitz, D.G. Tejeda, V. Duraj, J. Kabashima, R. Smith, E. Weber, High Risk Tasks for Musculoskeletal Disorders in Agricultural Field Work, IEA 2000/ HFES 2000 Congress, Vol. 3, HFES/IEA, San Diego, CA, 2000, pp. 616-619.

[57] J.M. Meyers, J.A. Miles, J. Faucett, I. Janowitz, D.G. Tejeda, J.N. Kabashima, Ergonomics in agriculture: workplace priority setting in the nursery industry, American Industrial Hygiene Association Journal 58 (2) (1997) 121126.

[58] K. Mobed, E.B. Gold, M.B. Schenker, Occupational health problems among migrant and seasonal farm workers, West J Med 157 (3) (1992) 367-373.

[59] J.R. Myers, Injuries Among Farm Workers in the United States, 1993, NIOSH, Cincinnati, OH, 1997, pp. 1-359.

[60] J.R. Myers, Injuries Among Farm Workers in the United States, 1995, NIOSH, Cincinnati, OH, 2001.

[61] N.A.S.S. NASS, 2002 Census of Agriculture, United States Department of Agriculture, Washington, D.C., 2003.

[62] K. Nickerson, Environmental contaminants in breast milk, J Midwifery Womens Health 51 (1) (2006) 26-34.

[63] L.M. Pastore, I. Hertz-Picciotto, J.J. Beaumont, Risk of stillbirth from occupational and residential exposures, Occup Environ Med 54 (7) (1997) 511-518.

[64] M. Plescia, H. Herrick, L. Chavis, Improving health behaviors in an African American community: the Charlotte Racial and Ethnic Approaches to Community Health project, Am J Public Health 98 (9) (2008) 16781684.

[65] G. Pransky, D. Moshenberg, K. Benjamin, S. Portillo, J.L. Thackrey, C. Hill-Fotouhi, Occupational risks and injuries in non-agricultural immigrant Latino workers, Am J Ind Med 42 (2) (2002) 117-123.

[66] S.A. Quandt, T.A. Arcury, A.I. Pell, Something for everyone? A community and academic partnership to address farmworker pesticide exposure in North Carolina, Environ Health Perspect 109 Suppl 3 (2001) 435-441.

[67] P. Rao, A.L. Gentry, S.A. Quandt, S.W. Davis, B.M. Snively, T.A. Arcury, Pesticide safety behaviors in Latino farmworker family households, Am J Ind Med 49 (4) (2006) 271-280.

[68] D.S. Rohlman, M. Lasarev, W.K. Anger, J. Scherer, J. Stupfel, L. McCauley, Neurobehavioral performance of 
adult and adolescent agricultural workers, Neurotoxicology 28 (2) (2007) 374-380.

[69] P.R. Salameh, B. Abi Saleh, Symptoms and acute pesticide intoxication among agricultural workers in Lebanon, J Med Liban 52 (2) (2004) 64-70.

[70] P.R. Salameh, I. Baldi, P. Brochard, B. Abi Saleh, Pesticides in Lebanon: a knowledge, attitude, and practice study, Environ Res 94 (1) (2004) 1-6.

[71] P.R. Salameh, M. Waked, I. Baldi, P. Brochard, B.A. Saleh, Chronic bronchitis and pesticide exposure: a case-control study in Lebanon, Eur J Epidemiol 21 (9) (2006) 681-688.

[72] E.M. Shipp, S.P. Cooper, K.D. Burau, J.N. Bolin, Pesticide safety training and access to field sanitation among migrant farmworker mothers from Starr County, Texas, J Agric Saf Health 11 (1) (2005) 51-60.

[73] S.D. Soechitram, M. Athanasiadou, L. Hovander, A. Bergman, P.J. Sauer, Fetal exposure to PCBs and their hydroxylated metabolites in a Dutch cohort, Environ Health Perspect 112 (11) (2004) 1208-1212.

[74] L.L. Strong, B. Thompson, T.D. Koepsell, H. Meischke, Factors associated with pesticide safety practices in farmworkers, Am J Ind Med 51 (1) (2008) 69-81.

[75] T.K. Takaro, L.S. Engel, M. Keifer, W.L. Bigbee, T.J. Kavanagh, H. Checkoway, Glycophorin A is a potential biomarker for the mutagenic effects of pesticides, Int $\mathrm{J}$ Occup Environ Health 10 (3) (2004) 256-261.

[76] UNDP, A Profile of Sustainable Human Development in Lebanon, United Nations Development Programme (UNDP), 1997.

[77] USDOL, California findings from the National Agricultural Workers Survey: A demographic and employment profile of perishable crop farm workers, United States Department of Labor (USDOL), Washington, D.C., 1993.

[78] USDOL, Findings from the National Agricultural Workers Survey (NAWS) 2001-2002: A Demographic and Employment Profile of United States Farm Workers, United States Department of Labor (USDOL), Washington, D.C., 2005.

[79] M.S. Vela Acosta, P. Chapman, P.L. Bigelow, C. Kennedy, R.M. Buchan, Measuring success in a pesticide risk reduction program among migrant farmworkers in Colorado, Am J Ind Med 47 (3) (2005) 237-245.

[80] D. Villarejo, The health of U.S. hired farm workers, Annu Rev Public Health 24 (2003) 175-193.

[81] D. Villarejo, Occupational Injury Rates Among Hired Farm Workers, Journal of Agricultural Safety and Health Special Issue (1) (1998) 39-46.

[82] D. Villarejo, S.L. Baron, The occupational health status of hired farm workers, Occup Med 14 (3) (1999) 613-635.

[83] D. Villarejo, D. Lighthall, D. Williams, A. Souter, R. Mines, B. Bade, S. Samuels, S. McCurdy, Suffering in silence: A report on the health of California's agricultural workers, California Institute for Rural Studies, 2000.

[84] D. Villarejo, S.A. McCurdy, The California Agricultural Workers Health Survey, J Agric Saf Health 14 (2) (2008) 135-146.

[85] D. Villarejo, M.B. Schenker, Environmental health policy and California's farm labor housing, University of California, Davis, 2006.

[86] S.G. Von Essen, S.A. McCurdy, Health and safety risks in production agriculture, West J Med 169 (4) (1998) 214-220.

[87] N. Walter, P. Bourgois, H. Margarita Loinaz, D. Schillinger, Social context of work injury among undocumented day laborers in San Francisco, J Gen Intern Med 17 (3) (2002) 221-229.
[88] M. Weselak, T.E. Arbuckle, W. Foster, Pesticide exposures and developmental outcomes: the epidemiological evidence, J Toxicol Environ Health B Crit Rev 10 (1-2) (2007) 41-80.

[89] M. Weselak, T.E. Arbuckle, D.T. Wigle, D. Krewski, In utero pesticide exposure and childhood morbidity, Environ Res 103 (1) (2007) 79-86.

[90] M. Weselak, T.E. Arbuckle, D.T. Wigle, M.C. Walker, D. Krewski, Pre- and post-conception pesticide exposure and the risk of birth defects in an Ontario farm population, Reprod Toxicol (2008)

[91] M.S. Wolff, S. Engel, G. Berkowitz, S. Teitelbaum, J. Siskind, D.B. Barr, J. Wetmur, Prenatal pesticide and PCB exposures and birth outcomes, Pediatr Res 61 (2) (2007) 243-250.

[92] M. Young, Migrant Workers in Lebanon, Lebanese NGO Forum, 2000.

[93] S.H. Zahm, A. Blair, Cancer among migrant and seasonal farmworkers: an epidemiologic review and research agenda, Am J Ind Med 24 (6) (1993) 753-766. 